\title{
A PROPÓSITO DE UM CASO DE MIASTENIA GRAVE
}

\section{JARBAS PERNAMBUCANO *}

Apesar de ser uma enfermidade há muitos anos conhecida, pois Wilks referiu a história de um caso em 1877, Erb isolou-a e Goldflam descreveu-a longamente, continua a ser ainda hoje, a miastenia grave, ou enfermidade de Erb-Goldflam, assunto de pesquisas e conjecturas por parte de inúmeros autores.

Trata-se de uma enfermidade que geralmente se inicia em adultos e cujo principal sintoma é a paralisia por fadiga, que ataca diferentes distritos do corpo. Esse ferômeno consiste em que os movimentos voluntários, quando repetidamente executados, caem em esgotamento após poucos minutos de exercício. Isso se verifica freqüentemente com os movimentos de deglutição, de mastigação, da marcha que, sendo repetidos, tornam-se impraticáveis, de tal fórma que o paciente amanhece bem, piorando às tardes. Os sintomas mais comuns são ptose palpebral acompanhada de lagoftalmo, disfagia, disforia, incapacidade de manter erecta a cabeça, fadiga fácil dos mùsculos do tronco ou dos membros, incluindo aí os movimentos para a marcha. A doença evolui geralmente para a morte em períodos variados. Está sujeita a remissões espontâneas, às vezes demoradas, ou a súbitas agravações. As complicações mais comuns que levam à morte correm por conta do ataque aos nervos bulbares. O diagnóstico é feito em vista dêsses transtornos motores, pelo exame elétrico e pela prova da prostigmira. O exame elétrico mostra, quase sempre, uma alteração qualitativa da resposta, reação miastênica de Jolly. Esta consiste no pronto esgotamento da capacidade reativa do músculo quando é excitado por corrente farádica de grande intensidade. Esse tipo de reação, embora não caraterístico da miastenia, pois tem sido encontrado em outras condições mórbidas, é mais ou menos con'stante na enfermidade de Erb-Goldflam. No caso que apresentamos, o diagnóstico foi confirmado pela prova da prostigmina, pois a excitação farádica dos músculos mais atingidos pela astenia não demonstrou a reação típica de Jolly. Esse é um dos pontos de interêsse desta comunicação.

* Docente de Clínica Neurológica da Fac. de Medicina do Recife. 
A etiologia da doença é pràticamente desconhecida. Têm sido vistos alguns casos pós-infecciosos - infecções gerais ou encefálicas pós-traumáticos, por fadiga, etc. $\mathrm{O}$ mecanismo patogênico, suposto verdadeiro até hoje, é bem interessante. Acredita-se haver, na miastenia, um defeito de transmissão na junção mioneural, defeito que incapacita a transmissão do impulso do nervo ao músculo. Sabe-se que, normalmente, a êsse nível, o nervo secreta uma substância, a acetilcolina, graças à qual é excitado o músculo. Isso se verifica no momento preciso em que se dá a passagem do impulso nervoso. Úma substância química, destrutiva, a colinesterase, controla o tempo de ação da acetilcolina, de tal forma que é preciso haver um equilibrio entre as duas substâncias para que se realize perfeita a função muscular. E justo nesse ponto que se verifica o descontrole na miastenia, doença em que o equilíbrio acetilcolin'a-colinesteràse está roto no sentido de uma predominância desta última, de tal fórma que se interrompe o movimento, apenas seja repetido. Teórica e pràticamente, na miastenia dá-se o contrário do que se passa na miotonia congênita ou doença de Thomsen cujo caraterístico clínico principal é a persistência tôrnica da contração muscular, consistindo o mecanismo íntimo dessa perturbação numa predominância da acetilcolina sôbre a colinesterase.

Quanto à participação de certas glândulas no mecanismo patológico da miastenia, muito se tem escrito. Uma das mais freqüentemente citadas é o timo, desde que, há 42 anos, Weigert descreveu um caso de tumor dessa glândula em paciente morto de miastenia. Norris, em mais de $50 \%$ dos casos de miastenia coligidos na literatura, notou comprometimento do timo sob a fórma de tumor ou simplesmente de hiperplasia. Acreditam alguns que o timo seja capaz, em determinadas condições patológicas, de secretar um hormônio que inibe a ação da acetilcolina. Resta saber, como diz Campbell ${ }^{1}$, e é o que importa - se a relação entre timo e miastenia é semelhante à da tireóide e bócio exoftálmico ou se é sòmente uma relação secundária, como se verifica em certos casos de bócio em que coexiste acromegalia. Henry Viets ${ }^{2}$ é contra a opinião de haver relações éntre o timo e miastenia, baseando sua idéia em dados clínicos. Assim é que, em 84 casos de miastenia, examinados radiològicamente, não emcontrou hipertrofia dessa glândula. $O$ fato é que, em bem poucos casos de miastenia com participação do timo, deu resultado a timectomia.

A terapêutica da enfermidade de Erb-Goldflam póde ser resumida ao emprêgo de três substâncias: a prostigmina, a efedrina e a guani-

1. Campbell, E., Fradkin, N. F. e Lipetz, B. - Myasthenia gravis treated by excision of thymic tumor. Arch. Neurol. a. Psychiat. 47:465, 1942.

2. Viets, H. R. - Present status of myasthenia gravis. Arch. Neurol. a. Psychiat. $47: 859,1942$. 
dina. A prostigmina (metilsulfato), que veio substituir o uso da fisostigmina de que é derivada, parece agir como inibidora da colinesterase. Os miastênicos suportam-na muito bem em doses mesmo elevadas. Poucas vezes notam-se sinais de intolerância para o lado do aparêlho digestivo. Isso pudemos comprovar no caso observado. A efedrina (sulfato) age também como inibidora da colinesterase, da mesma fórma que a guanidina (cloridrato). Com a primeira obtivemos bons resultados no caso que ora vamos tratar. A guanidina age menos que a prostigmina, segundo a opinião de Milhorat. Não chega a diminuir, em tão alto grau, como a prostigmina, o teor sanguíneo de colinesterase.

$\mathrm{O}$ caso que apresentamos, pertencente à clínica privada do Prof. Ulysses Pernambucano e que foi por nós observado no Sanatório Recife, em janeiro de 1942, ilustrará mais objetivamente o que foi dito acima.

Trata-se de um rapaz (J. F. P.) de 27 anos, branco, ex-soldado, que se apresentou à consulta dizendo-se doente há 2 anos desde quando vem sentindo dificuldade em falar e deglutir os alimentos, dificuldade que se apresentava invariàvelmente à tarde, demorando pouco. Passado o episódio voltava à normalidade. Essas crises, intervaladas e esporádicas a princípio, tornaram-se quase constantes, remitindo, apenas parcialmente, nas horas que seguiam o despertar do paciente, pela manhã.

Aos sintomas iniciais acrescentaram-se, ùltimamente, ptose palpebral (figura 1), fatigabilidade rápida para qualquer movimento, principalmente para os de caminhar, elevar os braços, cruzar as pernas, andar, sustentar a cabeça. O principal, entretanto, era o emagrecimento, que se acentuava de-

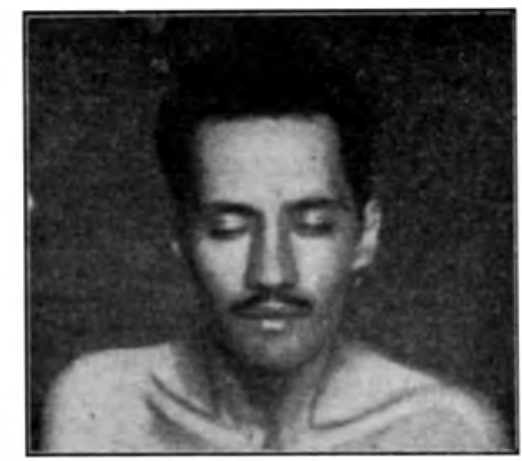

Fig, 1 - Fotografia de J. F. P. mostrando a ptose palpebral.

vido a grave irregularidade de deglutição, irregularidade que o impassibili. tava de ingerir alimentos sólidos ou líquidos, permitindo apenas a deglutição dos pastosos. Por isso, em casa, sua refeição obrigatória era pirão de girimú com mel de abelhas. Todas essas manifestações guardavam entre si 
um traço comum: o de diminuirem muito ou quase desaparecerem ao despertar.

$O$ estudo dos antecedentes familiares e pessoais do paciente nada demonstrou digno de nota. $O$ enfêrmo é nascido a têrmo de parto normal, tendo passado por todas as etapas evolutivas da infância sem incidentes. Somàtićamente trata-se de um longilíneo, com $1, \mathrm{~m} 72$ de altura e de 52 quilos de pêso, cujos aparelhos respiratório, circulatório e genito-urinário nada demonstravam de anormal. Pressão arterial: 11 e 6 .

Neurològicamente, chama a atenção a perturbação de deglutição e que consiste em não conseguir o paciente propulsionar o bôlo alimentar da bôca para as vias digestivas inferiores, a não ser estendendo exageradamente a cabeça sôbre o tronco (como o fazem as galinhas ao beberem água) para permitir o deslisamento dos alimentos pelo seu próprio pêso. Com a observação mais cuidadosa dos motivos dessa disfagia, evidencia-se que não só à língua, como também aos elevadores do faringe falta fôrça muscular para o desempenho de suas funções. A língua falta a elevação da ponta necessária à queda do bôlo alimentar no retrofaringe e, aos elevadores do faringe, o movimento executado pelas fibras constrictoras médias e inferiores, graças às quais alça-se todo o órgão para a recepção do alimento. $O$ esfôrço de deglutição do bário, visto radioscòpicamente, demonstra nitidamente o afirmado. Transposta a chamada fase voluntária da deglutição, ou melhor, chegado o bôlo à parte superior do faringe, tudo se continua bem.

Além do já descrito, apresenta ainda o paciente ptose palpebral e lagoftalmo bilaterais, voz nasalada, sem modulação, impossibilidade de flexão da cabeça quando se acha em decúbito dorsal, impossibilidade de estender a língua além da arcada dentária inferior, incapacidade de cruzar as pernas quando sentado, de elevar os braços estendidos. Todos êsses sinais de incapacidade motora são devidos à diminuição da resistência muscular à fadiga. Por exemplo, se se ordena ao enfêrmo sentar-se e levantar-se várias vezes de uma cadeira (movimento que executa com relativo desembaraço) consegue-o com agilidade nas primeiras duas ou três vezes, fracassando progressivamente até à incapacidade nas seguintes. E a paralisia por fadiga. Dai amanhecer melhor o doente, piorando à tarde. Não é demais insistir-se não haver no paciente paralisias verdadeiras mas uma pseudoparalisia, conseqüente à astenia muscular que impossibilita a repetição de movimentos. $O$ restante do exame neurológico nada apresenta de importância, a não ser diminuição do reflexo nauseoso ou faríngeo, sem disestesia da região. Estática, marcha, tôno e coordenação musculares, reflexos, sensibilidades, troficidade etc., nada apresentam que mereça registro. Um dos exames complementares realizados, foi o eletrodiagnóstico, que nada revelou de anormal. A reação miastênica de Jolly não foi encontrada.

Clinicamente, portanto, não havia dúvidas: tratava-se de um caso de miastenia. O eletrodiagnóstico, todavia, não demonstrou a reação peculiar à enfermidade. A confirmação do diagnóstico deu-a o teste da prostigmina, que foi realizado com meia empôla da substância, dose correspondente a 0,00025 . A prova foi realizada sem que o paciente soubesse ao que estava sendo submetido. Passados 20 minutos da injeção, feita às 11 horas, quando já passava mal, alguns movimentos, como os de deglutir, cruzar as pernas, elevar a cabeça acima do travesseiro, que não eram realizados, restabeleceram-se.

Pôsto assim o diagnóstico, foi instituida a terapêutica, que consistia no uso diário de duas empôlas de prostigmina (metilsulfato), tomadas às $11 \mathrm{e}$ às 17 horas. Isso livrava o paciente da sondagem esofagiana que realizávamos para a introdução de alimentos, duas vezes por dia. Diga-se de passa- 
gem que, graças à diminuição do reflexo nauseoso, essa operação era reaiizada com extrema facilidade, portando-se o enfêrmo como se fôra um manequim. Com o regime das duas empôlas diárias, foi permitido ao paciente voltar a seu domicílio no interior.

No dia 2 de fevereiro de 1943 voltou o paciente ao Sanatório, para revisão. Aumentara 10 quilos de pêso, tornara-se mais regular a pressão arterial, que era no momento de 13 e 7 . Durante as 48 horas em que esteve hospitalizado, dessa vez, foi suspenso o uso da prostigmina, o que trouxe, como resultado, voltar toda a antiga sintomatologia. Novo exame elétrico por meio da corrente farádica demonstrou, mais uma ve:, a inexistência da reação miastênica.

No dia 15 de maio de 1943 resolvemos modificar a medicação do paciente. Queixava-se êle não só do custo do medicamento, como do inconveniente de tomar obrigatòriamente dias injeções por dia. Foi empregado então o sulfato de efedrina na dose diária de 0,05 ; para isso empregamos o produto em cápsulas gelatinosas. Os resultados até hoje têm sido muito satisfatórios, embora conheçamos ser sujeita a doença a remissões espontâneas. Há quatro meses que vem gozando o enférmo de relativo bem-estar, superior àquele trazido pela prostigmina, fato que atestamos pessoalmente e através de cartas a nós enviadas. Em 25 de julho nos escrevia, por exemplo, dizendo: "a melhora é considerável, estando eu como era antes de adoecer".

\section{SUMARIO}

E relatada a observação de um caso de miastenia em adulto de 27 anos de idade, em cuja sintomatologia predominavam as perturbações da deglutição. Não foi possivel demonstrar a etiologia. $O$ exame neurológico resultou negativo, exceto para a astenia muscular. O exame clínico nada revelou de anormal. Não foram encontrados indícios de lesão do timo. $\mathrm{O}$ exame elétrico não demonstrou a reação de Jolly. A astenia diminuiu com a prostigmina e, também, com o emprêgo do sulfato de efedrina, em cápsulas gelatinosas, na dose diária de 0,05 centgrs.

\section{SUMMARY}

Case report of a 27 years old male with myasthenia in which there was a marked disturbance of swollowing. Etiology was not discovered. Neurological examination was negative, excepting the muscular asthenia. General clinical examination was negative. There were no signs of thymus pathology. Electric examination revealed a negative Jolly reaction. Improvement followed treatment with prostigmine combined with ephedrine sulfate in daily dosages of .05 centigrams.

Ruc Padre Inglês, 257 - Recife - Pernambuco. 